\title{
Significance of Lysosomes in the Morphogenesis of Coronaviruses*
}

\author{
By \\ R. Ducatelle and J. Hoorens \\ Department of Veterinary Pathology, \\ Faculty of Veterinary Medicine, \\ State University of Gent, Belgium \\ With 4 Figures \\ Accepted September 6, 1983
}

\section{Summary}

Virus-containing electron-dense membrane-bound cytoplasmic bodies are described in tracheal epithelial cells of chickens infected with Infectious Bronchitis Virus and in intestinal epithelial cells of swine infected with Porcine Epidemic Diarrhea Virus.

Using silver-methenamine staining, phosphotungstic acid staining and acid phosphatase enzyme cytochemical staining of ultra-thin sections, these bodies were shown to be virus-containing secondary lysosomes and residual bodies.

The accumulation of viral particles in the lysosomes is suggested to possibly represent an intracellular defense mechanism. However, no morphological alterations were found indicating a destruction of the viruses by the lytic lysosomal enzymes.

\section{Introduction}

Virus-containing electron-dense bodies (VEB) of a variable diameter are often described in cells infected with coronaviruses $(5,7,8,16,19,22,24)$.

In spite of their pleomorphism, these bodies have a number of common characteristics: they are electron-dense structures, limited by a unitmembrane and located in the cytoplasm. Their matrix may be amorphous or granulo-fibrillar. They seem to be particularly numerous after coronavirus

* Part of this work was presented as a thesis before the faculty of Veterinary Medicine at the State University of Gent. 
infection of the natural host cells $(7,8,24)$, although they are also obvious after coronavirus infection of cell cultures (5).

A number of authors have considered these structures to be viral factories $(7,19,24)$. Nevertheless, this would be in contradiction with the idea of coronaviruses being assembled exclusively by budding through endoplasmic reticulum membranes $(23)$.

These electron-dense bodies have also been suggested to represent lysosomes (2), possibly involved in the uptake and uncoating of the viral particles (5). Most authors describe these structures without giving any interpretation $(8,15,16)$.

None of the proposed hypotheses was ever proven.

This type of cellular alteration is not unique for coronaviruses. Both viral factories $(14,18,20)$ and virus-containing secondary lysosomes (4) have been described with other virus families. The purpose of the present study was to examine the nature of the electron-dense bodies and to study their possible role in the interaction between coronaviruses and their host cells. For this purpose, experimental infections were done with two coronaviruses, namely infectious bronchitis virus (IBV) in chickens and porcine epidemic diarrhea virus (PEDV) in pigs.

As a working hypothesis, the VEB were supposed to be of lysosomal origin. This hypothesis was based on the ultrastructural appearance of the bodies. Consequently, the morphologic criteria for the identification of lysosomes, as put forward by DAEMs et al., were tested (2).

\section{Materials and Methods}

Vimus Source

For the study of VEB in cells infected with IBV, chickens were inoculated with a commercially available H 52 strain of IBV (Intervet, Brussels, Belgium).

VEB were also studied in cells infected with the CV 777 strain of PEDV, after experimental inoculation of piglets. The isolation of this strain of PEDV has been described in detail (6).

\section{Animals}

Specific pathogen free (SPF) chickens of the Lohman breed, aged 20 to 30 weeks, and housed in isolators, were used for the experiments with IBV.

Caesarean-derived and colostrum-free piglets of the Belgian Landrace, aged 1 to 2 days, and housed in isolators, were used for the experiments with PEDV.

\section{Experimental Design}

Two groups of experiments were done with both viruses. Each time, a first group of experiments was done to provide material for pure morphological ultrastructural study, and a second group of experiments was done to provide material for ultrastruetural enzyme cytochemistry.

For morphological study of the VEB in chicken tracheal epithelial cells 10 SPF chickens were inoculated intratracheally with $10^{5}$ mean egg infective doses (EID 50 ) of the H52 strain of IBV, while 2 chickens were kept as controls. The animals were 
euthanatized at $19,20,21,22,23,24,25$ and 26 hours after inoculation. Further details of this experimental infection are given elsewhere (10).

The experiments done with the CV 777 strain of PEDV for morphological study have been described in association with the ultrastructural virus-induced lesions (9) and with the morphogenesis of the virus (8). Acid phosphatase cytochemistry was used as an enzymatic marker system for the VEB.

For this purpose, another group of $9 \mathrm{SPF}$ chickens were infected intratracheally with $10^{5} \mathrm{EID}_{50}$ of the $\mathrm{H} 52$ strain of IBV. The animals were kept in isolators and euthanatized in three groups at 24,25 and 27 hours after inoculation. A $10 \mathrm{~cm}$ cervical tracheal segment was fixed for 90 minutes in a solution containing 2 per cent glutaraldehyde and $0.1 \mathrm{M}$ cacodylate buffer. An additional 3 SPF chickens were used as controls. The tracheal segments of the controls were treated in the same way as the infected ones.

Three caesarean-derived and colostrum-free piglets were inoculated oronasally at 24 hours after birth with $2.10^{4}$ pig infective doses of the CV 777 isolate of PEDV (6). These three piglets were killed at the onset of clinical signs. One additional piglet was used as a control and killed at 48 hours after birth.

Several specimens from the middle of the jejunum of these piglets were fixed for 2 hours at $0^{\circ} \mathrm{C}$ in 2 per cent glutaraldehyde and $0.1 \mathrm{M}$ cacodylate buffer.

\section{Processing of the Materials}

Tissue specimens from the first group of experiments with both IBV and PEDV were processed for electron microscopy of ultra-thin sections as described earlier (8). Ultra-thin sections were cut and stained as described. Additional ultra-thin sections from the same blocks were bleached with periodic acid to remove osmium contrast. These sections were subsequently contrasted with silver-methenamine as described by SUZUKT and SeKTYAMA (12) or with phosphotungstic acid in aqueous solution (17).

Tissue specimens from the second group of experiments were immediately rinsed in distilled water after fixation. Thereafter the specimens were trimmed into $1 \mathrm{~mm}$ cubes. These blocks were then incubated in a medium containing $0.3 \mathrm{~g} \mathrm{~Pb}\left(\mathrm{NO}_{3}\right)_{2}$, $0.15 \mathrm{~g}$ sodium-beta-glycerophosphate and $0.05 \mathrm{~m}$ acetate buffer at $\mathrm{pH} 5.2$, for 90 minutes at $25^{\circ} \mathrm{C}$ (Deghezid, D., pers. comm.). Thereafter the blocks were rinsed in a solution containing 7.5 per cent sucrose and $0.05 \mathrm{M}$ acetate buffer. These blocks were subsequently dehydrated and embedded in Spurr's low viscosity medium as deseribed earlier (8). Ultra-thin sections were not counterstained with lead salts. Controls for the acid phosphatase reaction were done by omitting the sodium-beta-glycerophosphate and by adding $0.01 \mathrm{M} \mathrm{NaF}$ to the incubation medium.

\section{Results}

The virus morphogenesis and the ultrastructural appearance of VEB after PEDV inoculation of pig intestine have been described earlier (8). After IBV inoculation of chicken trachea, virus replication was most frequently seen 24 hours later in ciliated epithelial cells. Budding of viral particles was seen at endoplasmic reticulum membranes. The viral particles had a diameter of 60 to $100 \mathrm{~nm}$. They consisted of an outer unit-membrane and an inner electron-dense ring of 50 to $80 \mathrm{~nm}$ diameter and approximately $10 \mathrm{~nm}$ width. The central halo was moderately electron-translucent. These viral particles were present in distended endoplasmic reticulum cisternae, 


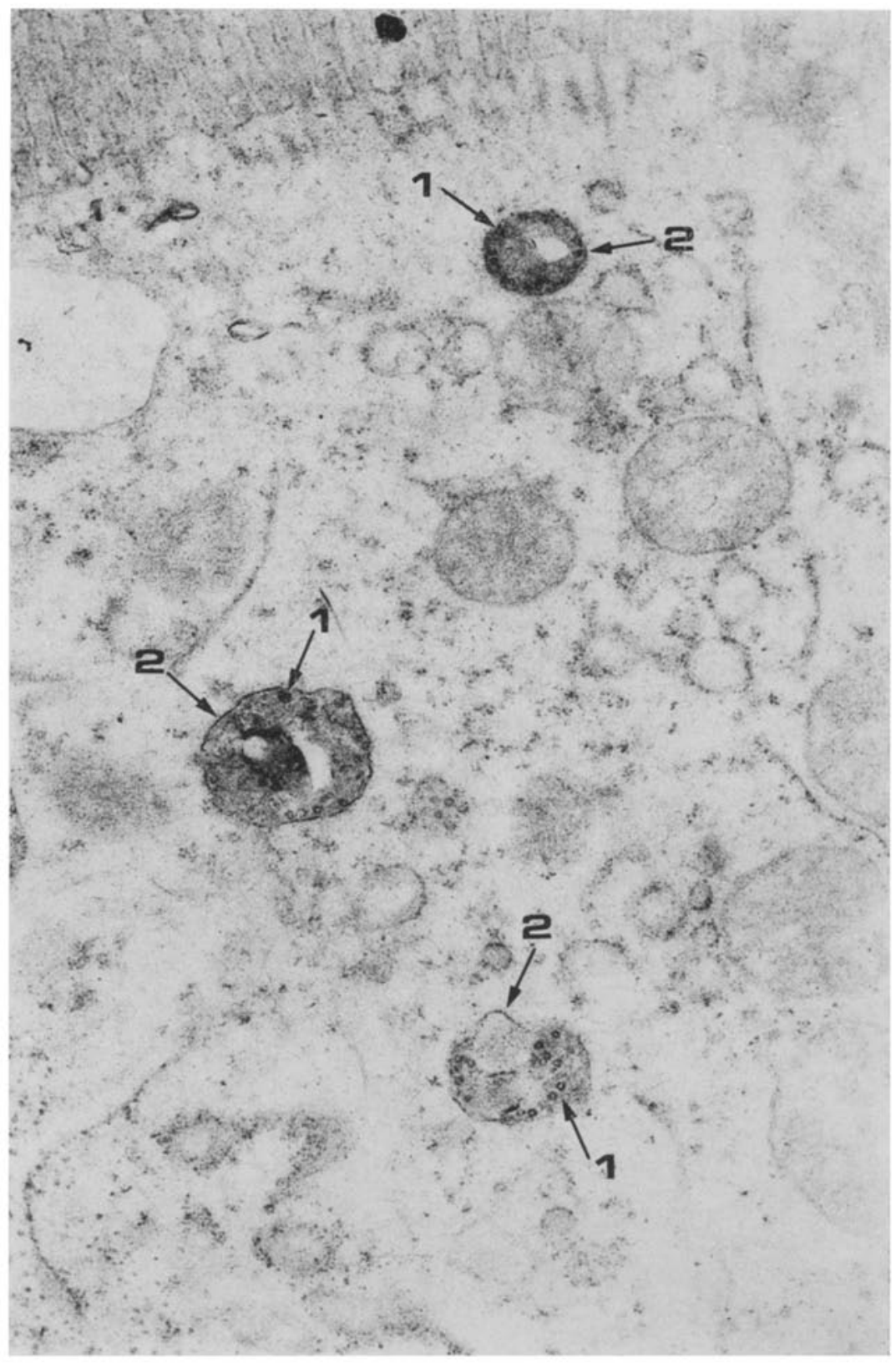

Fig. 1. Epithelial cell on a villus of the middle of the jejunum of a piglet, killed at 36 hours after inoculation with PEDV. The viral particles (1) and the membranes of the virus-containing electron-dense bodies (2) are intensely contrasted. Phosphotungstic acid technique, $\times 23,700$ 
in Golgi sacs, in small cytoplasmic vesicles and also in electron-dense membrane-bound cytoplasmic bodies (VEB). These VEB were usually round to oval, with a mean diameter of approximately $1.5 \mu \mathrm{m}$. On some occasions they were irregularly shaped, with viruses present inside bulges of the periphery. They contained a variable number of viral particles. The matrix of the VEB was finely granulo-fibrillar and electron-dense. The viral particles were either scattered in this matrix, or arranged in a row at the periphery. Some of these VEB were almost completely filled-up with viral particles. The VEB were limited by a unit-membrane, which was of a slightly larger diameter than the limiting membranes of other cell organelles. A marked clear halo of 20 to $60 \mathrm{~nm}$ width usually was present between the matrix and the limiting membrane.

In control non-infected tracheae, no viral particles and no VEB were seen in the epithelial cells.

Treatment of ultra-thin sections from both PEDV-infected and IBVinfected material with periodic acid yielded a complete disappearance of contrast.

After staining with phosphotungstic acid a limited number of cell organelles became contrasted. In non-infected pig intestinal epithelium the apical plasma membrane between the microvilli was slightly contrasted. The apical vesicular and tubular system was well contrasted. Also the nuclear chromatin and the cytoplasmic polyribosomes were faintly stained. The limiting membrane of primary lysosomes was heavily contrasted. In goblet cells, the mucus was highly electron-dense. Collagen fibers in the propria mucosae also were well contrasted.

In infected piglets, the same structures were contrasted. Moreover viral particles and the limiting membrane of theVEB were intensely stained (Fig. 1). The stroma of the VEB was weakly contrasted. In the tracheal epithelium of non-infected chickens a similar distribution of stain was observed as with control pig intenstinal epithelium.

In infected chickens phosphotungstic acid also stained the viral particles and the limiting membrane of the VEB in the ciliated epithelial cells. The stroma of the VEB was also faintly stained.

When periodic acid bleached ultra-thin sections were contrasted with silver-methenamine a limited number of cell organelles retained the silver grains.

In control non-infected pig intestines a slight silver stain was present on the plasma membranes and on the nuclear membranes. Nuclear chromatin, ribosomes and lysosomes were heavily stained. In the lysosomes both the limiting membrane and the stroma were positive. With silver-methenamine an electron-translucent rim between the lysosomal membrane and the matrix was clearly visible. The mucus of goblet cells and collagen bundles was also silver stained. 


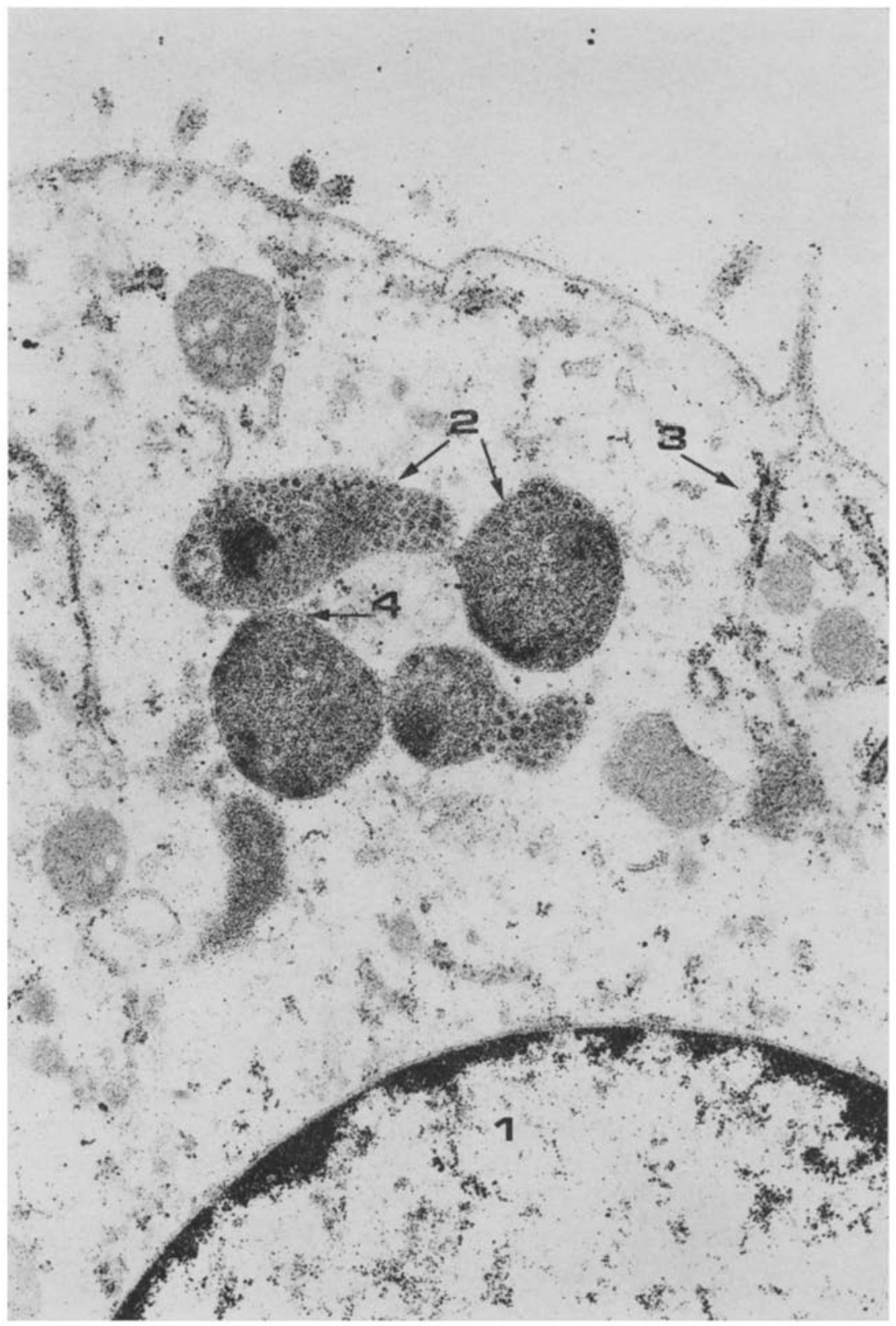

Fig. 2. Epithelial cell on a villus of the middle of the jejunum of a piglet, killed at 24 hours after inoculation with PEDV. The nucleus (1) and the virus-containing electron-dense bodies (2) are most intensely contrasted. Ribosomes (3) also are contrasted. Other cell organelles have little contrast. Note the narrow electrontranslucent rim between the limiting membrane and the stroma of the virus-containing electron-dense bodies ( 4 ). Silver-methenamine technique, $\times 23,700$ 
In infected pig intestinal epithelium the same structures were contrasted with the silver salts, plus the VEB and the viral particles (Fig. 2). An electrontranslucent rim was visible between the limiting membrane and the matrix of the VEB.

In control chicken tracheal epithelia the distribution of silver grains was comparable to that in control pig intestinal epithelial cells.

In infected chickens also the VEB and the viral particles were contrasted with silver-methenamine. Again there was a translucent rim under the limiting membrane of the VEB.

Acid phosphatase enzyme activity was demonstrated in ultra-thin sections by an electron-dense lead-phosphate precipitate.

In control non-infected pig intestine, acid phosphatase enzyme reaction product was observed in the lysosomal stroma of the epithelial cells. A positive reaction was also observed in the fenestrated sacs of the GERL system in the Golgi complex. Occasional endoplasmic reticulum strands contained a limited amount of enzyme reaction product. A moderate electrondense precipitate was found in the nucleus of the cells. This precipitate had a distribution similar to the heterochromatin.

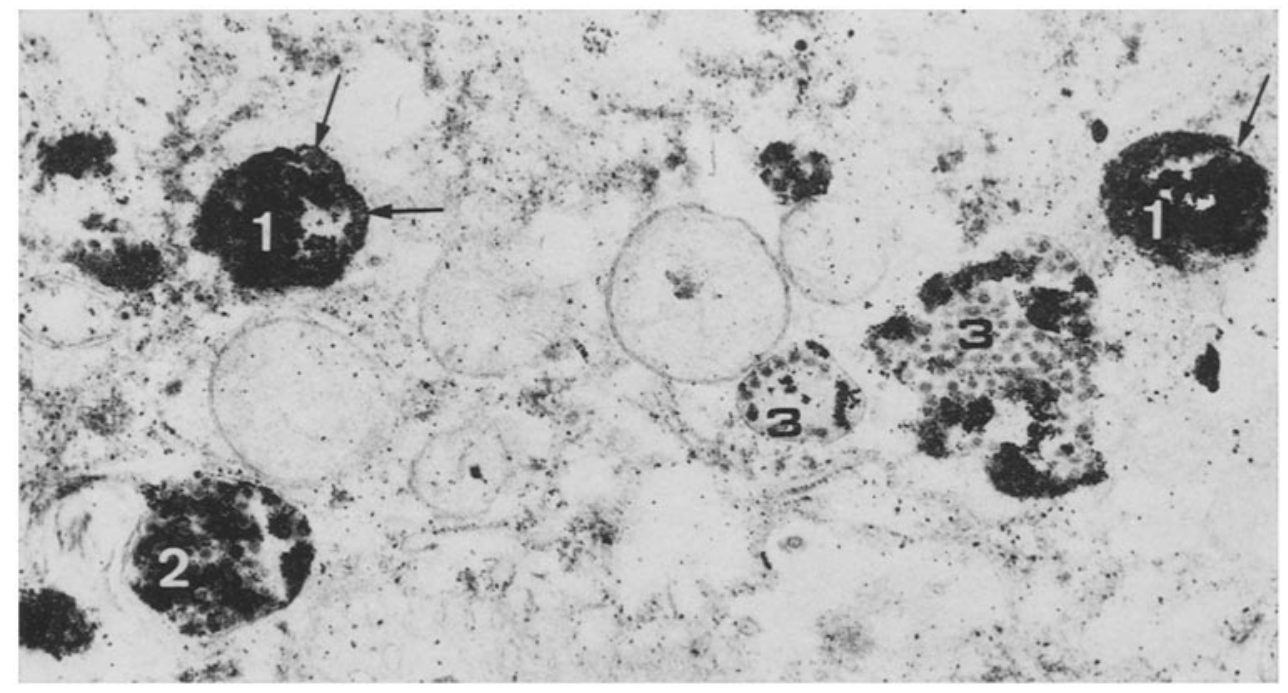

Fig. 3. Epithelial cell on a villus of the middle of the jejunum of a piglet, killed at 24 hours after inoculation with PEDV. Strongly acid phosphatase positive secondary lysosomes contain few viral partieles (1). These viral particles (arrows) are completely surrounded by the lead-phosphate precipitate. Lysosomes containing many viral particles are moderately acid phosphatase positive (2), whereas residual bodies which are heavily loaded with viral particles contain little acid phosphatase (3). Modified Gomori technique for the demonstration of aeid phosphatase enzyme activity, counterstained with uranylacetate, $\times 23,700$ 
In pig intestinal epithelial cells containing coronavirus particles, acid phosphatase enzyme reaction product was observed in the VEB (Fig. 3). The intensity of staining of the VEB was variable. VEB containing few viral particles were heavily stained. In contrast, VEB which were filled-up with viral particles only showed small patches of stain. Some VEB were completely negative for acid phosphatase. The viral particles were usually present in acid phosphatase negative gaps in the VEB. Golgi strucutres containing viral particles usually had a low or negative GERL acid phosphatase staining.

In control chicken tracheal epithelium the same organelles were positive for acid phosphatase as with control pig intestinal epithelium. In IBV infected tracheae the VEB were acid phosphatase positive. The distribution of the reaction product was very similar to that in PEDV infected pig intestines (Fig. 4).

Blocking the acid phosphatase enzyme activity with $\mathrm{NaF}$ or omitting the substrate from the reaction resulted in uncontrasted ultra-thin sections both in chicken tracheae and pig intestines with and without virus infection.

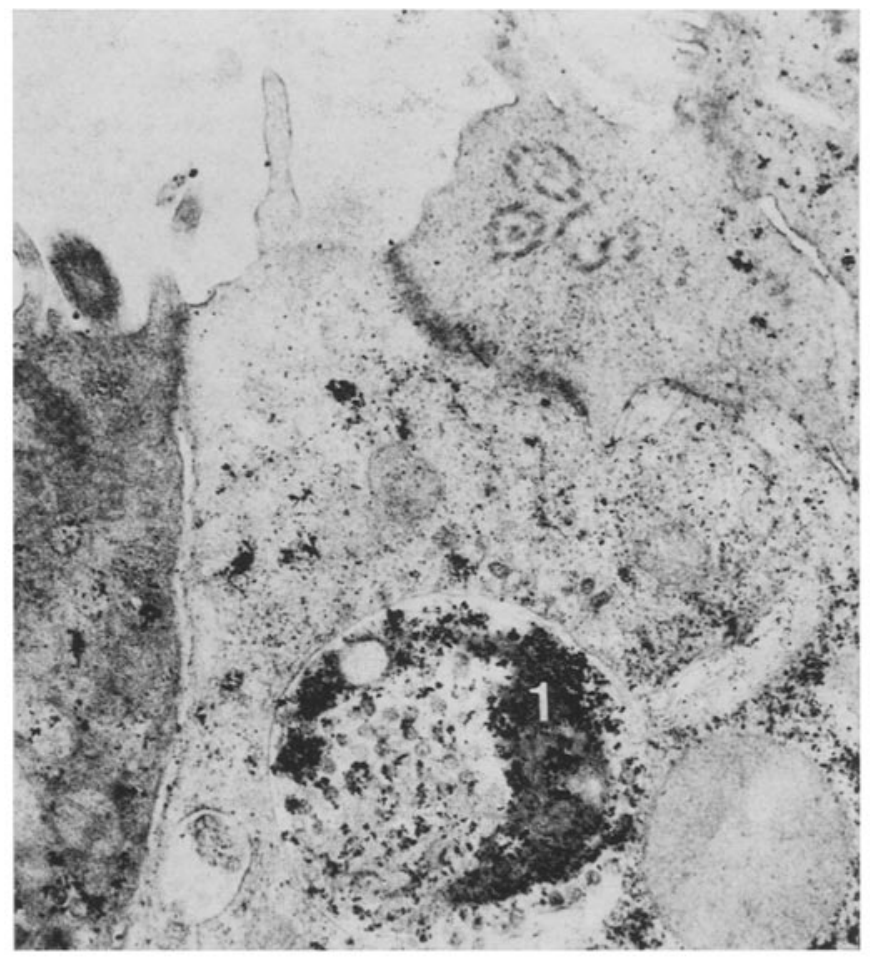

Fig. 4. Epithelial cell in the trachea of a chicken, killed at 25 hours after inoculation with the $\mathrm{H} 52$ strain of IBV. Acid phosphatase positive virus-containing secondary lysosome (1). Modified Gomori technique for the demonstration of acid phosphatase enzyme activity, counterstained with uranylacetate, $\times 23,700$ 


\section{Discussion}

The results of the acid phosphatase enzyme cytochemistry and the silvermethenamine and phosphotungstic acid staining techniques indicate that the VEB in cells infected with PEDV or with IBV most probably are lysosomes, as proposed in the working hypothesis. The results were very similar for PEDV and for IBV.

The ultrastructural morphological characteristics of lysosomes (2) were present in the VEB. Most significant here was the presence of an electrontranslucent rim between the thick limiting membrane and the granulofibrillar stroma, as was observed after silver-methenamine staining.

Biochemically, the acid phosphatase enzyme is the model enzyme for the group of acid hydrolases and its presence is considered to be the standard criterion for determining an organelle as a lysosome (11). Nevertheless, the absence of acid phosphatase does not preclude an organelle being of lysosomal origin. Acid phosphatase is present in significant amounts only in lysosomes and in the GERL region of the Golgi apparatus. Small amounts are present in a limited number of ER strands $(2,13)$. This was also observed in the control tracheal and intestinal epithelial cells of the present study. Acid phosphatase thus is a useful marker enzyme for lysosomes (2). Other lysosomal acid hydrolases have a more variable intracellular distribution and techniques for the demonstration of these enzymes are less reliable. Consequently, other acid hydrolases were less indicated as marker enzymes for our purpose. Acid phosphatase was demonstrated in many of the VEB in the present material using lead phosphate as an electron-dense marker.

The phosphotungstic acid and silver-methenamine techniques were useful alternatives to enzyme cytochemistry since they stained lysosomes fairly specifically. The advantage of these techniques is that they can be applied to routinely fixed and embedded materials. They are particularly helpful for the detection of acid phosphatase negative residual bodies.

The intensity of the acid phosphatase reaction was inversely proportional to the number of viral particles present in the VEB. This is in accordance with the cytochemistry of secondary lysosomes, which lose their acid phosphatase enzyme activity when "aging" (2). The acid phosphatase negative VEB could thus be considered to be virus-filled residual bodies, although this cannot be proved, since residual bodies lack specific markers.

The role of the VEB in cells infected with coronaviruses is difficult to define. Lysosomes have been suggested to play a role in uncoating following the uptake of viral particles $(1,3,5)$. Viral particles inside lysosomes may thus come from outside the cell. In the present material the virus-containing lysosomes were present in cells with many viral particles and with signs of active virus multiplication. This suggests that the viral particles in the lysosomal matrix can also be newly formed viral particles. 
The viruses possibly enter the lysosomes by fusion of virus-containing vesicles with lysosomes. Presence of viruses at the periphery of the VEB and inside bulges of the VEB limiting membrane support this viewpoint. It is also possible though that coronavirus particles and acid phosphatase enzyme are packaged together as they leave the GERL region of the Golgi apparatus, since both are thought to follow the same path, traversing the Golgi structure from the cis to the trans side. The low acid phosphatase content of the virus-containing Golgi structures nevertheless pleads against this viewpoint.

Anyway, secondary lysosomes seem to accumulate coronavirus particles in cells infected with IBV or with PEDV. This could represent an intracellular host defense mechanism. Nevertheless, the lytic acid phosphatase enzyme does not cause any appreciable alteration of the morphology of the viral particles.

In the present material, virus-containing Golgi structures usually had a low acid phosphatase activity. The Golgi apparatus thus probably has little hydrolysing effect on the viruses. It rather has a role in packaging of the viral particles into secretory vacuoles $(8,21)$. In normal cells, glycosylation is one of the major functions of the Golgi complex (13). In cells infected with coronaviruses, envelope proteins of the viruses become glycosylated during intracellular transport $(19,21)$. A second function of the Golgi complex in the morphogenesis of coronaviruses may thus be glycosylation of the envelope proteins. This would be in accordance with the observation of transport through and accumulation of coronavirus particles in the Golgi sacs $(7,8)$.

In conclusion, virus-containing electron-dense cytoplasmic bodies were frequently seen in the late stages of infection of cells with IBV and with PEDV. These bodies were probably lysosomes accumulating viral particles. They may represent an intracellular defense mechanism which segregates the viral particles from the host cell cytoplasm. The lytic lysosomal enzymes nevertheless seem to be unable to destroy the accumulated viruses.

\section{Acknowledgements}

The authors thank Dr. G. Meulemans and Dr. P. Debouck for their help with the experimental work. Prof. Dr. J. M. V. M. Mouwen, Prof. Dr. M. B. Pensaert, Prof. Dr. H. Lauwers and Prof. Dr. H. Roels are acknowledged for helpful discussion of the results. The technical assistance of Mr. J. P. Logghe for ultramicrotome preparations was much appreciated.

\section{References}

1. Altison, A.: Lysosomes in virus-infected cells. Perspect. Virol. 5, 29-61 (1967).

2. Daems, W. T., Wisse, E., Brederoo, P.: Electron microscopy of the vacuolar apparatus. In : Dingle, J. T. (ed.), Lysosomes, a laboratory handbook. AmsterdamLondon: North-Holland 1972. 
3. DALEs, S., KaJIOKA, R.: The cycle of multiplication Vaccinia virus in Earle's strain $L$ cells. I. Uptake and penetration. Virology 24, 278-294 (1964).

4. DÄмmRICH, K., Loppnow, H.: Regressive Veränderungen. In: Stunzi, H., Weiss, E. (eds.), Allgemeine Pathologie für Tierärzte und Studierende der Tiermedizin. Berlin-Hamburg: Paul Parey 1982.

5. David-Ferretra, J. F., Manaker, R. A.: An electron microscope study of the development of a mouse hepatitis virus in tissue culture cells. J. Cell Biol. 24, $57-78(1965)$.

6. Debouck, P., Pensakrt, M.: Experimental infection of pigs with a new porcine enteric Coronavirus, CV 777. Am. J. Vet. Res. 41, 219-223 (1980).

7. Doughri, A. M., Storz, J., Hajer, I., Fernando, H. S.: Morphology and morphogenesis of a coronavirus infecting intestinal epithelial cells of newborn calves. Exp. Molec. Pathol. 25, 355-370 (1976).

8. Ducathlle, R., Coussement, W., Pensaert, M. B., Debouck, P., Hoorens, J.: In vivo morphogenesis of a new porcine enteric coronavirus CV 777. Arch. Virol, 68, $35-44(1981)$.

9. Ducatelde, R., Coussement, W., Deboudk, P., Hoormas, J.: Pathology of experimental CV 777 coronavirus enteritis in piglets. II. E.M. study. Vet. Pathol. 19, $57-66(1982)$.

10. Dudatel.te, R.: Cytopathology and Virusmorphogenesis in Coronavirus infections. Commun. Fac. Vet. Med., State Univ. Ghent 25, 1-254 (1983).

11. Duve, C. DE: General properties of lysosomes, the lysosome concept. In: DE REUCK, A. V. S., Cameron, M. P. (eds.), Ciba foundation symposium of lysosomes. London: J. and A. Churchill 1963.

12. Geyer, G.: Elektronenmikroskopische Histochemie (Teil I). In: GravmanN, W., Neumann, K. (eds.), Handbuch der Histochemie. Stuttgart-New York: G. Fischer 1977.

13. Goldfischer, S.: The internal reticular apparatus of Camillo Golgi : A complex, heterogeneous organelle, enriched in acid, neutral, and alkaline phosphatases, and involved in glycosylation, secretion, membrane flow, lysosome formation, and intracellular digestion. J. Histochem./Cytochem. 30, 717-733 (1982).

14. Krvge, J. P., Cheville, N. F., Peery, T. M. : Ultrastructural studies of Contagious Ecthyma in sheep. Am. J. Vet. Res. 33, 1191-1200 (1972).

15. Mebus, C. A., Statr, E. L., Rhodes, M. B., Twiehaus, M. J.: Pathology of neonatal calf diarrhea induced by a coronavirus-like agent. Vet. Pathol. 10, 45-64 (1973).

16. Pensaert, M. B., Haemterman, E. O., Hinsman, E. J.: Transmissible-Gastroenteritis of swine: virus-intestinal cell interactions. II Electron microscopy of the epithelium in isolated jejunal loops. Areh. ges. Virusforseh. 31, 335-351 (1970).

17. QUATACKen, J.: Endocytosis and multivesicular body formation in rabbit luteal cells during pseudopregnancy. Cell Tiss. Res. 161, 541-553 (1975).

18. Richter, W. R., MoIze, S. M.: Ultrastructural nature of canine distemper inclusions in the urinary bladder. Pathol. Vet. 7, 346-352 (1970).

19. Robb, J. A., Bond, C. W.: Coronaviridae. In: Conrat, H. F., Wagner, R. R. (eds.), Comprehensive Virology, Vol. 14, 193-247. 1979.

20. SAIF, L. J., TheIL, K. W., BоHL, E. H.: Morphogenesis of porcine rotavirus in porcine kidney cell cultures and intestinal epithelial cells. J. gen. Virol. 39, 205-217 (1978).

21. Siddelt, St., WfGe, H., Ter Mevlen, V.: The structure and replication of coronaviruses. Carr. topies Mierobiol. Immunol. 99, 131-163 (1982).

22. ThAKe, D. C.: Jejunal epithelium in transmissible gastroenteritis of swine. An electron microscopic and histochemical study. Am. J. Pathol. 53, 148-158 (1968). 
23. Tyrrell, D. A. J., Alfixander, D. J., Almeida, J. D., Cunningham, C. H., Easterday, B. C., Garwes, D. J., Hrerholzer, J. C., Kapikian, A., MacNAJGhton, M. R., MoIntosh, K.: Coronaviridae: second report. Intervirol. 10, $321-328(1978)$.

24. Uppal, P. K., ChU, H. P.: An electron microscope study of the trachea of the fowl infected with avian infectious bronchitis virus. J. Med. Microbiol. 3, 643-647 (1970).

Authors" address: Dr. R. Ducatelle, Department of Veterinary Pathology, Faculty of Veterinary Medicine, State University of Gent, Casinoplein 24, B-9000 Gent, Belgium.

Received July 11, 1983 